\title{
Alpha-Gal Glycosphingolipids
}

National Cancer Institute

\section{Source}

National Cancer Institute. Alpha-Gal Glycosphingolipids. NCI Thesaurus. Code C78200.

A preparation of glycosphing olipids (GSL), containing the disaccharide epitope galactosealpha-1,3-galactose (alpha-Gal), with potential antineoplastic activity. Upon intratumoral injection, alpha-Gal glycosphingolipids may stimulate the immune system to mount complement-mediated cytotoxicity (CMC) and antibody-dependent cell-mediated cytotoxicity (ADCC) responses against alpha-Gal GSL, which may result in tumor cell death; these responses involve natural anti-alpha-Gal immunoglobulins (Igs). As antibodies that occur naturally due to sensitization to alpha-Gal present on symbiotic bacterial flora, anti-alpha-Gal Igs are present in unusually high amounts in human sera. GSL represent a glycolipid subtype containing the amino alcohol sphingosine; tumorassociated GSL antigens contain various oligosaccharide residues. 